\title{
Rapid and Specific Detection of Burkholderia glumae in Rice Seed by Real- Time Bio-PCR Using Species-Specific Primers Based on an rhs Family Gene
}

\author{
Byoung Kyu Kim, Min Seok Cho, Myeong Ho Kim, Hyeon Jin Choi, Man Jung Kang, and Hong Sik Shim, National Academy of \\ Agricultural Science, Rural Development Administration, 441-707 Suwon, Republic of Korea; Tae-Young Ahn, Department of \\ Microbiology, Dankook University, 330-71, Cheonan, Republic of Korea; Jaisoo Kim, Department of Life Science, Kyonggi Univer- \\ sity, Suwon 443-760, Republic of Korea; and Dong Suk Park, National Academy of Agricultural Science, Rural Development \\ Administration, 441-707 Suwon, Republic of Korea
}

\begin{abstract}
Kim, B. K., Cho, M. S., Kim, M. H., Choi, H. J., Kang, M. J., Shim, H. S., Ahn, T.-Y., Kim, J., and Park, D. S. 2012. Rapid and specific detection of Burkholderia glumae in rice seed by real-time Bio-PCR using species-specific primers based on an rhs family gene. Plant Dis. 96:577-580.

In this study, we developed a reliable, quick, and accurate quantitative polymerase chain reaction ( $\mathrm{qPCR}$ ) assay to detect grain rot caused by Burkholderia glumae in rice seed. The control of bacterial grain rot is difficult, and the only practical methods for disease management rely on the use of pathogen-free seed, appropriate culture practices, and resistant cultivars. Therefore, the specific detection of this pathogen in seed is essential for effective control of the disease. However, other Burkholderia spp. are also detected by currently available molecular and serological methods. In this study, we exploited the available genome sequence information in public databases to develop specific

PCR primers for accurate diagnosis of B. glumae. An SYBR Green real-time PCR primer set was designed based on the rhs family gene (YD repeat protein) of $B$. glumae BGR1 because these genes are structurally diverse. The specificity of the primers was evaluated using purified DNA from 5 isolates of $B$. glumae, 6 different species of Burkholderia, and 18 other reference pathogenic bacteria. The assay was able to detect at least one genome equivalent of cloned amplified target DNA using purified DNA or 1 CFU per reaction when using calibrated cell suspension. This method is rapid and reliable and has great potential for analyzing large numbers of samples.
\end{abstract}

Bacterial grain rot of rice caused by the bacterium Burkholderia glumae is a frequent cause of yield loss on certain cultivars in Korea, Japan, the United States, and other rice-growing areas around the world. The pathogen also causes seedling rot in nursery boxes and is one of the most important bacterial rice pathogens $(2,16)$. Yield losses of $15 \%$ are common, and losses of $80 \%$ have been recorded in severely infected fields (4). This disease is highly dependent on weather conditions at the flowering stage (19). In recent years, its incidence has increased in rice-growing regions of many Southeast Asian countries, the Americas, and Africa. Meanwhile, it was revealed that $B$. gladioli also causes gain rot and seedling rot, and appeared to cause $20 \%$ of bacterial panicle blight in the United States $(7,14,20)$. In addition, it was reported that $B$. glumae is also an important opportunistic human pathogen for chronic granulomatous disease patient (21).

Unfortunately, some rice cultivars currently grown in Korea are susceptible to B. glumae to varying degrees. In addition, the control of bacterial grain rot is difficult, and the only practical methods for disease management rely on the use of pathogen-free seed, appropriate culture practices, and resistant cultivars. Therefore, the specific detection of this pathogen in seed is essential for effective control of the disease. However, there have been few efficient detection methods for $B$. glumae from rice thus far. In order to effectively manage the disease and prevent the pathogen from spreading, it is urgent to establish an accurate, rapid, and practical method for detection of $B$. glumae from rice.

Currently, molecular assays based on the 16S-23S rDNA spacer region, $g y r B$, and $r p o D$ are used for the detection of $B$. glumae $(12,14,17)$ but there have been critical defects in the diagnosis and identification of $B$. glumae isolates, in that these assays also detect

Corresponding author: D. S. Park, E-mail: dspark@rda.go.kr

Accepted for publication 9 November 2011.

http://dx.doi.org/10.1094/PDIS-03-11-0235

(C) 2012 The American Phytopathological Society other Burkholderia spp. such as Ralstonia spp. because 16S-23S rDNA internal transcribed spacer regions are highly conserved in genomes at a level of species or genus. Therefore, we have investigated $r h s$ family genes (YD repeat proteins) to develop more specific primers for identifying B. glumae. The nucleotide sequences of the gene were assessed for specificity and variety among Burkholderia spp. through BLASTN searches. In this study, we designed species-specific primers based on the rhs family gene (YD repeat protein) of $B$. glumae BGR1 and found that the primer set showed high specificity for detecting the pathogen in rice seed. It is reported that $R h s$ repertoires (YD repeat proteins) are ubiquitous and comprise six structurally distinct lineages within the family Enterobacteriaceae, and there is considerable intergenomic variation in $R h s$ repertoire (8). These results revealed that this real-time polymerase chain reaction (PCR)based method can be used for rapid detection of B. glumae, simplifying diagnosis, monitoring of this pathogen, and guiding of plant disease management.

\section{Materials and Methods}

Bacterial strains, culture condition, and DNA preparation. Bacterial strains were obtained from the Korean Agricultural Culture Collection in Republic of Korea, the Belgian Coordinated Collections of Micro-organisms, the National Collection of Plant Pathogenic Bacteria in the United Kingdom, and the American Type Culture Collection (ATCC) in the United States. All microorganisms used in this study are listed in Table 1. The conditions for culturing of all bacterial species were as recommended in the Handbook of Microbiological Media (1). Total DNA from microorganisms was extracted using the bacterial genomic DNA extraction kit supplied by Qiagen (Qiagen, Hilden, Germany). All purified DNAs were quantified on a NanoDrop ND-1000 spectrophotometer (NanoDrop Technologies, Wilmington, DE).

Primer design and conventional PCR. A primer set was designed for an rhs family gene (YD repeat protein) of B. glumae BGR1 (GenBank accession number 237878396), with predicted PCR products of $138 \mathrm{bp}$ (Table 2). Conventional PCR assays were performed with a PTC-225 thermocycler (MJ Research, Water- 
town, MA). All amplifications were carried out in a final volume of $50 \mu \mathrm{l}$ containing $20 \mathrm{mM}$ Tris- $\mathrm{HCl}, 100 \mathrm{mM} \mathrm{KCl}, 50 \%$ glycerol, 0.1 mM EDTA, $1 \mathrm{mM}$ dithiothreitol, $0.5 \%$ Tween 20 , $0.5 \%$ Nonidet P40, $1 \mathrm{mM}$ PMSF, $0.2 \mathrm{mM}$ each dNTP, $20 \mathrm{pM}$ each primer, 2 units of Taq polymerase (SolGent, Daejeon, Republic of Korea), and approximately $25 \mathrm{ng}$ of genomic DNA from a given microorganism. Reactions were run for 35 cycles, each consisting of $60 \mathrm{~s}$ at $94^{\circ} \mathrm{C}, 30 \mathrm{~s}$ at $63^{\circ} \mathrm{C}$, and $60 \mathrm{~s}$ at $72^{\circ} \mathrm{C}$, with an initial denaturation of 5 min at $94^{\circ} \mathrm{C}$ and a final extension of $10 \mathrm{~min}$ at $72^{\circ} \mathrm{C}$. A $10-\mu \mathrm{l}$ aliquot of each amplified PCR product was electrophoresed on a $1.5 \%$ agarose gel, stained with LoadingStar (DYNEBIO, Republic of Korea), and visualized with a UV transilluminator.

SYBR Green real-time PCR assay. The SYBR Green real-time PCR assay was performed in a $20-\mu l$ reaction volume containing KAPA SYBR FAST qPCR Master Mix (2x) Universal (KAPA Biosystem, Inc.). Each PCR reaction contained $10 \mu \mathrm{l}$ of KAPA SYBR qPCR Master MIX Universal, 5 pM each BG1F/R, and $5 \mathrm{ng}$ of cloned DNA from each sample. Amplification was carried out using the CFX96 real-time PCR system (Bio-Rad Laboratories, Hercules, CA), and the thermal cycling parameters were as follows: $95^{\circ} \mathrm{C}$ for $3 \mathrm{~min}, 45$ cycles of $95^{\circ} \mathrm{C}$ for $10 \mathrm{~s}$ and $63^{\circ} \mathrm{C}$ for $20 \mathrm{~s}$, and a melting curve of 65 to $95^{\circ} \mathrm{C}$ with an increment of $0.5^{\circ} \mathrm{C}$. A copy number of the cloned DNA was calculated with the following equation: $\operatorname{copies} / \mu \mathrm{l}=\left[6.022 \times 10^{23}(\mathrm{copy} / \mathrm{mol}) \times\right.$ amount $\left.(\mathrm{g})\right] /$ [length $(\mathrm{bp}) \times 660(\mathrm{~g} / \mathrm{mol} / \mathrm{bp})](5)$.
Detection of pathogen by Bio-PCR. The rice (Oryza sativa 'Odae') seed affected with bacterial grain rot were collected from Icheon, Gyeonggi province, Republic of Korea in August 2011. Depending on the degree of grain rot severity in rice seed, five grains from naturally infected seed lots sampled in rice fields were selected and each grain was soaked in $500 \mu \mathrm{l}$ of sterile distilled water for $30 \mathrm{~min}$. Then, $2 \mu \mathrm{l}$ from the water treated with each single grain was used in SYBR Green real-time and conventional PCR assays as described above.

\section{Results}

Sequence specificity of designed primers. Specificity of the primer set designed from an rhs family gene (GenBank accession number 237878396) was tested in silico by similarity search against the sequence database at the National Center for Biotechnology Information (http://www.ncbi.nlm.nih.gov/). It showed some significant matches with previously determined sequences (BLASTN ver. 2.2.25+). BLASTN searches showed similarity to rhs family protein (identity $=79 \%$, score $=3,065$ bits $[3,398]$, and expect $=0.0$ ) from B. multivorans ATCC 17616. BLAST searches with the predicted protein sequence (BLASTX) revealed similarity to YD repeat-containing protein (identity $=$ $81 \%$, score $=1,988$ bits $[5,150]$, and expect $=0.0)$ from $B$. multivorans ATCC 17616. However, the C-terminal sequence region to be amplified with the designed primer set (Table 2)

Table 1. Bacterial strains used in this study and results by conventional polymerase chain reaction assays

\begin{tabular}{|c|c|c|c|c|c|}
\hline \multirow[b]{2}{*}{ Scientific name ${ }^{b}$} & \multirow[b]{2}{*}{ Collection $^{c}$} & \multirow[b]{2}{*}{ Origin } & \multicolumn{3}{|c|}{ Primer sets $^{a}$} \\
\hline & & & BG1F/R & Glu-FW/Glu-RW (12) & Forward/reverse (17) \\
\hline Burkholderia glumae ${ }^{\mathrm{T}}$ & LMG 2196 & Japan & + & + & + \\
\hline B. glumae & LMG 6952 & Japan & + & + & + \\
\hline B. glumae & LMG 10905 & Japan & + & + & + \\
\hline B. glumae & LMG 10906 & Japan & + & + & + \\
\hline B. glumae & LMG 1277 & Japan & + & + & + \\
\hline B. gladioli $^{\mathrm{T}}$ & LMG 2216 & United States & - & - & - \\
\hline B. plantarii $^{\mathrm{T}}$ & LMG 9035 & Japan & - & + & - \\
\hline B. cepacia $^{\mathrm{T}}$ & LMG 1222 & United States & - & - & - \\
\hline B. caryophylli ${ }^{\mathrm{T}}$ & LMG 2155 & United States & - & - & + \\
\hline B. andropogonis ${ }^{\mathrm{T}}$ & LMG 2129 & United States & - & - & + \\
\hline B. cenосерасіа $^{\mathrm{T}}$ & KACC 12021 & United Kingdom & - & - & + \\
\hline Acidovorax avenae subsp. avenae ${ }^{\mathrm{T}}$ & NCPPB 1011 & Unknown & - & - & - \\
\hline Xanthomonas oryzae pv. oryzae ${ }^{\mathrm{T}}$ & LMG 5047 & India & - & - & - \\
\hline$X$. oryzae pv. oryzicola ${ }^{\mathrm{T}}$ & LMG 797 & Malaysia & - & - & - \\
\hline$X$. campestris pv. campestris ${ }^{\mathrm{T}}$ & LMG 568 & United Kingdom & - & - & - \\
\hline Pseudomonas syringae pv. oryzae ${ }^{\mathrm{T}}$ & KACC 10133 & Unknown & - & - & + \\
\hline P. syringae pv. japonica ${ }^{\mathrm{T}}$ & LMG 5068 & Japan & - & - & - \\
\hline P. jessenii ${ }^{\mathrm{T}}$ & ATCC 700870 & France & - & - & - \\
\hline P. libanesis ${ }^{\mathrm{T}}$ & KACC 10809 & Lebanon & - & - & - \\
\hline P. mucidolens ${ }^{\mathrm{T}}$ & LMG 2223 & United States & - & - & - \\
\hline P. oryzihabitan ${ }^{\mathrm{T}}$ & LMG 7040 & Japan & - & - & - \\
\hline P. fuscovaginae ${ }^{\mathrm{T}}$ & LMG 2158 & Japan & - & - & - \\
\hline P. ludensis ${ }^{\mathrm{T}}$ & LMG 13517 & Unknown & - & - & - \\
\hline Ralstonia solanasearum ${ }^{\mathrm{T}}$ & LMG 2299 & US & - & - & - \\
\hline Erwinia persicina $^{\mathrm{T}}$ & LMG 11254 & United Kingdom & - & - & - \\
\hline E. tracheiphila ${ }^{\mathrm{T}}$ & LMG 2707 & Japan & - & - & - \\
\hline Pectobacterium chrysanthemi ${ }^{\mathrm{T}}$ & LMG 2804 & United States & - & - & - \\
\hline P. carotovora subsp. carotovorum ${ }^{\mathrm{T}}$ & LMG 2404 & Denmark & - & - & - \\
\hline Escherichia coli ${ }^{\mathrm{T}}$ & LMG 2092 & Unknown & - & - & - \\
\hline
\end{tabular}

a BG1F/R, this study; + and - indicates species was detected or not detected, respectively.

$\mathrm{b} \mathrm{T}=$ type strain.

c Collection number: LMG, The Belgian Coordinated Collections of Micro-organisms, Belgium; KACC, Korean Agricultural Culture Collection, Republic of Korea; NCPPB, The National Collection of Plant Pathogenic Bacteria, United Kingdom; ATCC, The American Type Culture Collection, United States.

Table 2. Primers used in this study

\begin{tabular}{llcc}
\hline Primer & \multicolumn{1}{c}{ Sequences $\left(\mathbf{5}^{\prime} \mathbf{- 3}\right)$} & Annealing temperature $\left({ }^{\circ} \mathbf{C}\right)$ & Amplicon size $(\mathbf{b p})$ \\
\hline BG1F & CCGCGCTGTTCATGAGGGATAA & 63 & 138 \\
BG1R & CGGGCGGAACGACGGTAAGT & $\ldots$ & $\ldots$ \\
Forward & ACGTTCAGGGATRCTGAGCAG & 60 & $\ldots$ \\
Reverse & AGTCTGTCTCGCTCTCCCGA & $\ldots$ & $\ldots$ \\
Glu-FW & GAAGTGTCGCCGATGGAG & 63 & $\ldots$ \\
Glu-RW & CCTTCACCGACAGCACGCAT & $\ldots$ & $\ldots$ \\
\hline
\end{tabular}


revealed no significant matches in both BLASTN and BLASTX searches.

Specificity test of primers. The primer set BG1F/R was tested by conventional PCR against five isolates of B. glumae. As expected, a 138-bp DNA fragment was amplified (Fig. 1). To check the specificity of the primers, a large collection of other microorganisms, including other Burkholderia spp., was tested by SYBR Green real-time PCR with the BG1F/R primer set. All B. glumae strains gave a consistent positive result regardless of the existence of other species of the pathogen; only B. glumae strains showed a single amplified DNA fragment (Table 1).

Sensitivity test by SYBR Green real-time PCR. The SYBR Green real-time PCR standard curve constructed by plotting the mean threshold cycle $\left(\mathrm{C}_{\mathrm{T}}\right)(n=3)$ versus logarithmic concentrations of (ranging from $5 \times 10^{6}$ to $5 \times 10^{0} \mathrm{fg} / \mu \mathrm{l}$; cloned DNA) displayed a good linearity of response $\left(R^{2}=0.994\right)$. The detection limit of the reaction was less than $5 \times 10^{0}$ plasmid copies of $B$. glumae. Standard regression analyses of the linear part of the slope gave a coefficient of -2.972 and the PCR efficiency calculated from the slope of the standard curve was $117.0 \%$. Analysis of melting temperature $(\mathrm{Tm})$ and melting peak on SYBR Green real-time PCR of $B$. glumae showed a reproducible $\mathrm{Tm}$ of $81.50^{\circ} \mathrm{C}$ specific peaks. A sensitivity test was performed using a 10 -fold dilution series of genomic DNA and cell suspension of the pathogen. The minimum detection level of genomic DNA and cell suspension by SYBR green real-time PCR assay was

Table 3. Mean threshold cycle $\left(\mathrm{C}_{\mathrm{T}}\right)$, end-point fluorescence, and 10-fold serially diluted Burkholderia glumae genomic DNA and cell suspensions by SYBR Green real-time polymerase chain reaction

\begin{tabular}{lcccc}
\hline Genomic DNA & & & \multicolumn{2}{c}{ Cell suspensions } \\
\cline { 1 - 2 } \cline { 5 - 5 } $\mathbf{f g} / \boldsymbol{\mu l}$ & $\mathbf{C}_{\mathbf{T}}$ values & & $\mathbf{C F U} / \mathbf{m l}$ & $\mathbf{C}_{\mathbf{T}}$ values \\
\hline $5 \times 10^{6}$ & $16.24 \pm 0.25$ & & $1.0 \times 10^{8}$ & $18.65 \pm 0.41$ \\
$5 \times 10^{5}$ & $18.75 \pm 0.03$ & & $1.0 \times 10^{7}$ & $21.33 \pm 0.26$ \\
$5 \times 10^{4}$ & $22.22 \pm 0.08$ & & $1.0 \times 10^{6}$ & $24.43 \pm 0.08$ \\
$5 \times 10^{3}$ & $25.85 \pm 0.08$ & & $1.0 \times 10^{5}$ & $27.98 \pm 0.31$ \\
$5 \times 10^{2}$ & $28.91 \pm 0.2$ & & $1.0 \times 10^{4}$ & $31.56 \pm 0.40$ \\
$5 \times 10^{1}$ & $32.41 \pm 0.2$ & & $1.0 \times 10^{3}$ & $34.98 \pm 0.59$ \\
$5 \times 10^{0}$ & $35.00 \pm 0.3$ & & $1.0 \times 10^{2}$ & $37.25 \pm 0.87$ \\
\hline
\end{tabular}

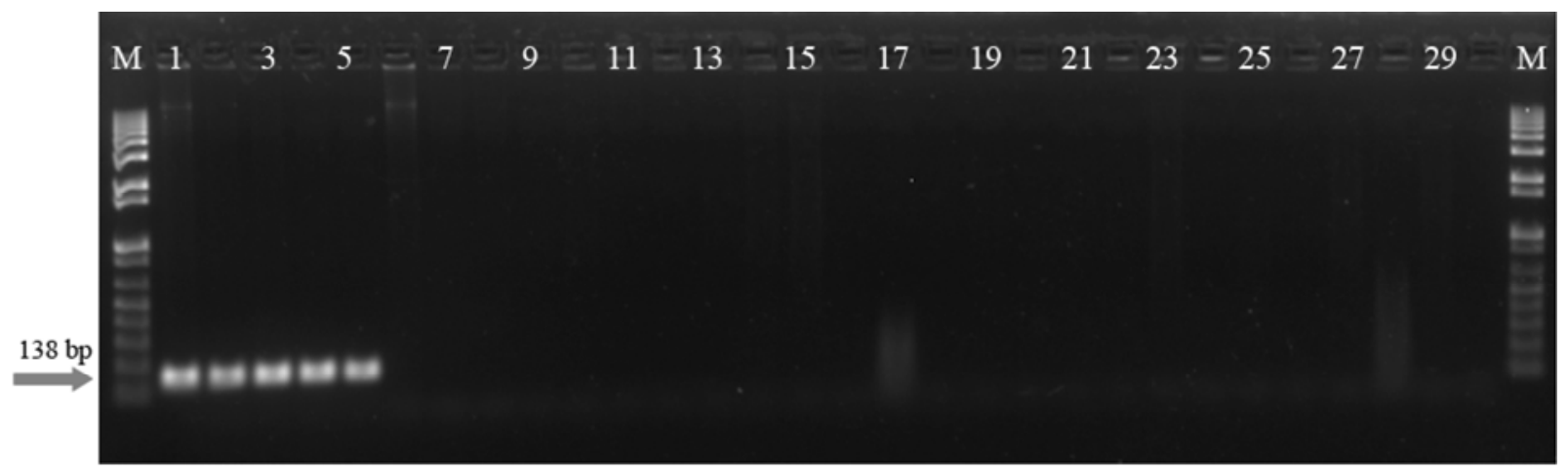

Fig. 1. Specific detection of Burkholderia glumae by conventional polymerase chain reaction. Lane M, size marker (1 kb plus DNA ladder); lanes 1-5, B. glumae; lanes 6-29, listed in Table 2; lane 30, negative control (distilled water).

A

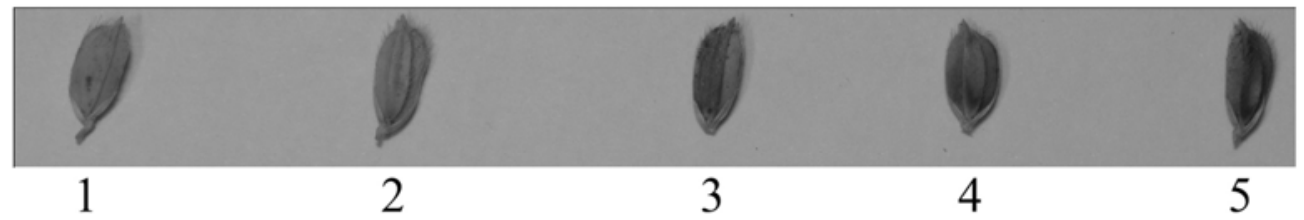

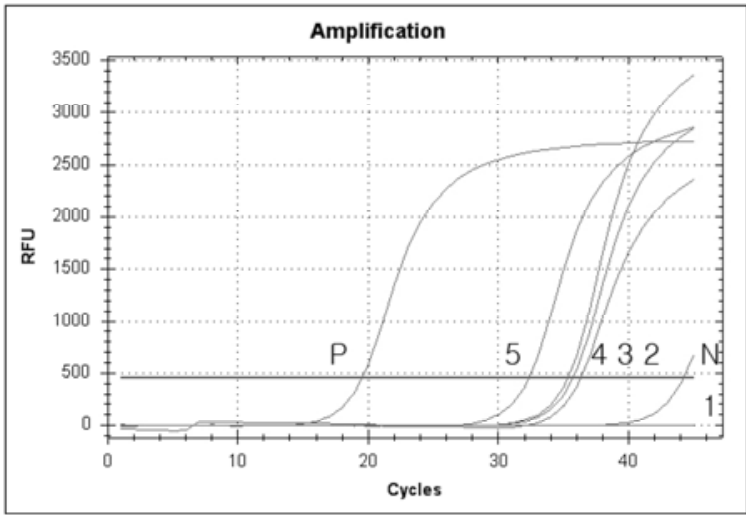

$\mathrm{C}$

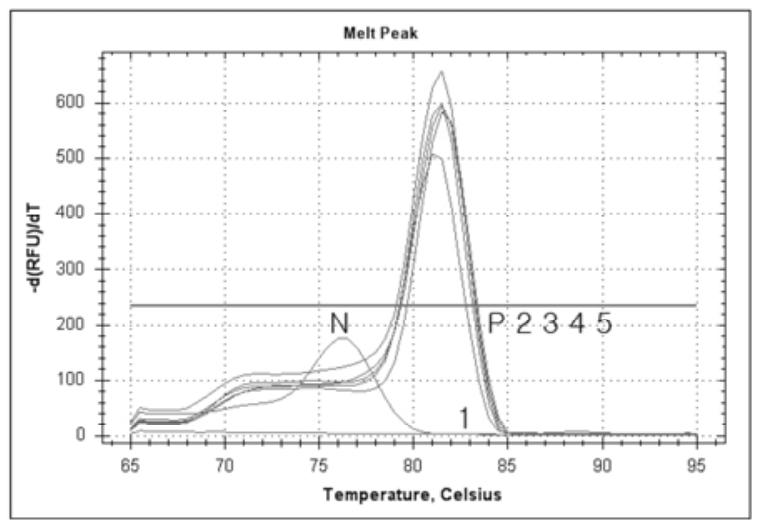

Fig. 2. Naturally infected rice grains and specific detection of Burkholderia glumae by SYBR Green real-time polymerase chain reaction (PCR). A, Severity of disease symptoms and nonsymptoms in rice grain. B, Fluorescence intensity as function of templates. For each assay, a series of rice grains were used as the template for PCR. C Melting curve analysis showed a reproducible melting temperature of $81.50^{\circ} \mathrm{C}$ and specific peaks. RFU = relative Florence units. (P, Burkholderia glumae genomic DNA; 1 , nonsymptomatic sample; $2-5$, symptomatic samples; N, no template). 
approximately $5 \times 10^{0} \mathrm{fg} / \mu \mathrm{l}$ copies and $1 \times 10^{2} \mathrm{CFU} / \mathrm{ml}$ of $B$. glumae, respectively. Standard curves showed that there was a linear correlation between the $\mathrm{C}_{\mathrm{T}}$ values and the concentrations of input DNA or cell suspension, which ranged from genomic DNA $\left(R^{2}=0.997\right.$, slope $\left.=-3.225\right)$ to cell suspension $\left(R^{2}=0.993\right.$, slope $=-3.222)$ of the pathogen (Table 3$)$.

Detection of the pathogen by Bio-PCR in infected rice seed. The primer set developed in this study was tested against B. glumae. The detection results of $B$. glumae from each grain sampled from naturally infected seed lots were presented (Fig. 2). As expected, a 138-bp DNA fragment from the infected grain samples was amplified by real-time PCR. On the other hand, no single DNA fragment was amplified from the control.

\section{Discussion}

The results presented in this study describe the development of effective assays for the reliable detection of $B$. glumae. Although the classical microbiological techniques currently in use for $B$. glumae detection and identification are satisfactory in most situations, more rapid and reliable tests may be useful in some specific situations $(10,13)$. Detection methodologies for pathogenic bacteria have benefited greatly from modern molecular technology involving specific amplification of target DNA fragments $(3,9,17)$.

Recently, development of specific primers from the 16S-23S rDNA spacer region for identification and detection has been reported for B. glumae $(4,17,18)$. However, the molecular identification of Burkholderia spp. is often difficult and controversial $(3,15)$. The sequence analyses of the $16 \mathrm{~S}$ rRNA gene, $g y r B$, and $r p o D$ are widely employed for the identification of bacteria $(6,7,11,12)$. However, these regions are insufficient to discriminate between the species of Burkholderia $(12,17)$.

In fact, detection of pathogen in nonsymptomatic seedlings is of importance in certification programs, for both domestic and international quarantine, because a latent population can lead to serious epidemics under favorable conditions. Early detection of diseases is important for assessing the health status of a rice nursery before the transplantation of seedlings to fields.

Therefore, in this study, species-specific primers from the whole-genome sequences of B. glumae BGR1 (GenBank accession number CP001504.1), deposited in GenBank (ftp://ftp.ncbi.nih. gov/genomes/Bacteria/), were designed. The rhs family gene (YD repeat protein) (GenBank accession number 237878396) was analyzed by BLAST searches and found to be highly variable in different bacteria at the species level.

It is reported that $R h s$ repertoires (YD repeat protein) are ubiquitous and comprise six structurally distinct lineages within the family Enterobacteriaceae, and there is considerable intergenomic variation in $R h s$ repertoire (8). Successful detection of different strains of $B$. glumae but not other phytopathogenic bacteria further suggests that the specificity of primer set $B G 1 F / R$ to this pathogen may be due to its unique sequence.

There is a common problem in the appearance of unspecific amplification bands or curves when cell suspensions or tissue extracts are used directly for PCR, hampering interpretation of the results. However, no spurious band (curve) was observed in any of the samples analyzed in this investigation using this primer set. This result indicates that the primer set developed through the bioinformatics method is highly specific to B. glumae and reliable for the detection and diagnosis of this pathogen.

\section{Acknowledgments}

This study was supported by a grant from Rural Development Administration, Suwon, Republic of Korea.

\section{Literature Cited}

1. Atlas, R. M. 2004. Handbook of Microbiological Media, 3rd ed. CRC Press, Boca Raton, FL.

2. Azegami, K., Nishiyama, K., Watanabe, Y., Kadota, I., Ohuchi, A., and Fukasawa. 1987. Pseudomonas plantarii sp. nov., the causal agent of rice seedling blight. Int. J. Syst. Bacteriol. 37:144-152.

3. Drevínek, P., Hrbácková, H., Cinek, O., Bartosová, J., Nyc, O., Nemec, A., and Pohunek, P. 2002. Direct PCR detection of Burkholderia cepacia complex and identification of its genomovars by using sputum as source of DNA. J. Clin. Microbiol. 40:3485-3488.

4. Fang, Y., Xu, L., Tian, W., Yan, H., Yu, S., Lou, M. M., and Xie, G. L. 2009. Real-time fluorescence PCR method for detection of Burkholderia glumae from rice. Rice Sci. 16:157-160.

5. Fu, J., Li, D., Xia, S., Song, H., Dong, Z., Chen, F., Sun, X., and Tang, Z. 2009. Absolute quantification of plasmid DNA by real-time PCR with genomic DNA as external standard and its application to a biodistribution study of an HIV DNA vaccine. Anal. Sci. 25:675-680.

6. Gee, J. E., Sacchi, C. T., Glass, M. B., De, B. K., Weyant, R. S., Levett, P. N., Whitney, A. N., Hoffmaster, A. R., and Popovic, T. 2003. Use of 16 S rRNA gene sequencing for rapid identification and differentiation of Burkholderia pseudomallei and B. mallei. J. Clin. Microbiol. 41:4647-4654.

7. Ham, J. H., Melanson, R. A., and Rush, M. C. 2011. Burkholderia glumae: next major pathogen of rice? Mol. Plant Pathol. 12:329-339.

8. Jackson, A. P., Thomas, H. T., Parkhill, J., and Thomson, N. R. 2009. Evolutionary diversification of an ancient gene family (rhs) through Cterminal displacement. BMC Genomics 10:584.

9. Kaestli, M., Mayo, M., Harrington, G., Watt, F., Hill, J., Gal, D., and Currie, B. J. 2007. Sensitive and specific molecular detection of Burkholderia pseudomallei, the causative agent of melioidosis, in the soil of tropical northern Australia. Appl. Environ. Microbiol. 73:6891-6897.

10. Kawanishi, T., Shiraishi, T., Okano, Y., Sugawara, K., Hashimoto, M., Maejima, K., Komatsu, K., Kakizawa, S., Yamaji, Y., Hamamoto, H., Oshima, K., and Namba, S. 2011 New detection systems of bacteria using highly selective media designed by SMART: Selective medium-design algorithm restricted by two constraints. PLoS One 27:6:e16512.

11. Lee, C. S., and Lee, J. 2010. Evaluation of new gyrB-based real-time PCR system for the detection of $B$. fragilis as an indicator of human-specific fecal contamination. J. Microbiol. Methods 82:311-318.

12. Maeda, Y., Shinohara, H., Kiba, A., Ohnishi, K., Furuya, N., Kawamura, Y. Ezaki, T., Vandamme, P., Tsushima, S., and Hikichi, Y. 2006. Phylogenetic study and multiplex PCR-based detection of Burkholderia plantarii, Burkholderia glumae and Burkholderia gladioli using gyrB and $r p o D$ sequences. Int. J. Syst. Evol. Microbiol. 56:1031-1038.

13. Miller, S.A., Beed, F. D., and Harmon, C. L. 2009. Plant disease diagnostic capabilities and networks. Annu. Rev. Phytopathol. 47:15-38.

14. Nandakumar, R., Shahjahan, A. K. M., Yuan, X. L., Dickstein, E. R., Groth, D. E., Clark, C. A., Cartwright, R. D., and Rush, M. C. 2009. Burkholderia glumae and B. gladioli cause bacterial panicle blight in rice in the southern United States. Plant Dis. 93:896-905.

15. Ramette, A., LiPuma J. J., and James, M. T. 2005. Species abundance and diversity of Burkholderia cepacia complex in the environment. Appl. Environ. Microbiol. 71:1193-1201.

16. Rush, M. C., Shao, Q. M., Zhang, S., Shahjahan, A. K., O'Reilly, K., Shih, D., Groth, D., and Linscombe, S. D. 2003. Biotechnology and control of rice diseases. La. Agric. 46:20-23.

17. Sayler, R. J., Cartwright, R. D., and Yang, Y. 2006. Genetic characterization and real-time PCR detection of Burkholderia glumae, a newly emerging bacterial pathogen of rice in the United States. Plant Dis. 90:603-610.

18. Takeuchi, T., Sawada, H., Suzuki, F., and Matsuda, I. 1997. Specific detection for Burkholderia plantarii and B. glumae by PCR using primers selected from the 16S-23S rDNA spacer regions. Ann. Phytopathol. Soc. Jpn. 63:455-462.

19. Tsushima, S., Naito, H., and Koitabashi, M. 1996. Population dynamics of Pseudomonas glumae, the causal agent of bacterial grain of rice, on leaf sheaths of rice plants in relation to disease development in the field. Ann. Phytopathol. Soc. Jpn. 62:108-113.

20. Ura, H., Furuya, N., Iiyama, K., Hidaka, M., Tsuchiya, K., and Matsuyama, N. 2006. Burkholderia gladioli associated with symptoms of bacterial grain rot and leaf-sheath browning of rice plants. J. Gen. Plant Pathol. 72:98-103.

21. Weinberg, J. B., Alexander, B. D., Majure, J. M., Williams, L. W., Kim, J. Y., Vandamme, P., and LiPuma, J. J. 2007. Burkholderia glumae infection in an infant with chronic granulomatous disease. J. Clin. Microbiol. 45:662665 . 